cuya cobertura ha sido más bien escasa debido a la falta de una política de salud consecuente y de un sistema integral y a las limitaciones de la capacidad gerencial. También mostraron necesidades relativamente amplias las áreas 9 de Nuevo León, y 16 y 17 en Tamaulipas, con -2 .

Con respecto a los indicadores del uso de los servicios, las AMGD 12 y 14 en Tamaulipas y la 3 en Coahuila fueron las menos usadas para atención preventiva con $-4,-3$ y -2 , respectivamente. En esas áreas, la población acude a otras instituciones del sector para la detección de enfermedades y la planificación familiar.

La distribución de recursos materiales para la atención de salud fue muy variada. Las AMGD con menos recursos fueron la 17 en Tamaulipas y las 1 y 4 en Coahuila, con índices $Z$ de $-4,-3$ y -2 , respectivamente. La 17 está en una zona fronteriza donde hay diferentes industrias de ensamblaje y la asignación de trabajadores a las unidades médicas de familia es esporádica, lo que hace difícil estimar la respuesta a esa necesidad. En relación con ello se detectan otras faltas de equidad, como un número dispar de unidades de laboratorio y salas de radiología. En este caso, las áreas más necesitadas fueron la número 4 y otras de Coahuila. Sin embargo, si se considera que en México el estándar es de 0,10 unidades de laboratorio por $1000 \mathrm{DH}$ y el de salas de radiología de 0,26 por $1000 \mathrm{DH}$, casi todas las áreas eran deficientes. Con respecto a las camas disponibles, la AMGD 8 en Nuevo León fue la más afectada, con 0,28 camas por $1000 \mathrm{DH}$, cifra mucho más baja que la del país en general (1,2 por 1000 habitantes). Países como el Canadá cuentan con 5,8 camas por 1000 habitantes, pero aun países en desarrollo como Haití tienen por lo menos 1,5 camas por 1000 . Por otro lado, las áreas de Tamaulipas resultaron deficientes en la disponibilidad de consultorios, comparadas con las de Nuevo León.

En cuanto al estado de salud, las AMGD más afectadas fueron la 9 en Nuevo León con un índice $Z$ de -3; la 12 en Tamaulipas con -2; y la 14 en Tamaulipas con -1 . Estos índices pueden considerarse el resultado de necesidades no satisfechas, especialmente en áreas rurales, y superaron aun los años de vida saludable perdidos en los estados de Chiapas, Guerrero y Puebla, donde existe la mayor marginación. Esto revela que las desigualdades pueden estar enmascaradas en lugares pequeños.

La mayor atención de salud per cápita correspondió a la AMGD 12 en Tamaulipas, con una dotación de US\$ 168,90, seguida de la 13 en Tamaulipas, $(\$ 164,35)$ y la 2 de Coahuila $(\$ 146,45)$. Las más necesitadas fueron varias áreas de Nuevo León y la 17 de Tamaulipas. Nuevo León es un estado receptor con una alta inmigración de Tamaulipas, San Luis Potosí, Coahuila y Zacatecas, lo cual genera desequilibrios de diversa magnitud incluso en la salud por falta de datos fidedignos para proyeccio- nes de población. De acuerdo con los gastos en servicios, la AMGD 9 de Nuevo León estaba en tercera posición según las necesidades de salud; pero en gastos per cápita, su decimosegunda posición reflejaba la falta de equidad en ese rubro. La misma falta de concordancia se reveló en las AMGD 17 y 16 de Tamaulipas, 4 de Coahuila y 8 de Nuevo León. Por contraste, la AMGD 2 de Coahuila presentó la mejor condición según las necesidades de salud y una posición privilegiada en cuanto a gastos por atención médica.

En Nuevo León, Coahuila y Tamaulipas se está poniendo en efecto una reforma basada en la descentralización. Se espera que el desarrollo regional y establecimiento ulterior de las AMGD resuelva las crisis relacionadas con el aumento de los costos, y la falta de eficiencia y equidad. La distribución de recursos tiene que responder a las necesidades de cada estado de la región. Se proyecta establecer un sistema de información geográfica adaptable a cualquier ambiente y usar los indicadores que resulten de este trabajo. Se podrían así registrar los cambios estructurales de la población. Esta propuesta, insisten los autores, puede aplicarse a cualquier institución del sector de la salud, siempre que el área geográfica sea pequeña. Como paso inicial, permitiría relacionar la distribución económica con las necesidades de salud, ya que es preciso primero medirlas antes de aplicar el principio de equidad a los recursos.

Será difícil lograr la equidad en situaciones locales mientras no se descentralice la organización y se siga dependiendo de decisiones estratégicas. Además, no se sabe hasta qué punto el sector de la salud podrá liderar el proceso frente a la cultura gerencial. Urge ejecutar políticas dirigidas a lograr la equidad, estimular la participación intersectorial para mejorar la vida y el estado de salud de la población, y realizar la reforma con una perspectiva integral enfocada en las personas y en lograr un desarrollo humano sostenible. (Núñez Rocha GM, et al. Resource allocation equity in northeastern Mexico. Health Pol. 2004; 70:271-9.)

\section{¿Puede omitirse el desayuno sin perjuicio para la salud?}

El efecto del desayuno en las concentraciones de colesterol, triglicéridos, insulina y ácido úrico en la sangre es de continuo interés, por ser su alteración un factor de riesgo de la enfermedad cardiovascular. Según varios estudios, el consumo de desayuno se relaciona de forma negativa con la obesidad. En un ensayo clínico se estratificó al azar a mujeres obesas en un grupo que desayunaba y otro que ayunaba. Las participantes que inicialmente ayunaban perdieron más peso desayunando, mientras que las que antes tomaban desayuno perdieron más peso omi- 
tiéndolo. Otro ensayo reveló que los adultos que consumían cereales precocidos de paquete tenían ingestas diarias significativamente menores de grasas y colesterol que los que comían otros alimentos para el desayuno o ayunaban. En otros dos estudios se ha confirmado que, cuando el desayuno contiene cereales, la ingesta diaria total y de grasas saturadas se reduce, lo que reduce también el colesterol.

En algunos ensayos se ha investigado el efecto del ayuno en las concentraciones de lípidos séricos. En estudios epidemiológicos, el consumo de cereales integrales no refinados se asoció con índices más bajos de la masa corporal y menores concentraciones de colesterol sérico total, colesterol de las lipoproteínas de baja densidad e insulina. También se observó que la ingesta de cereal integral tiende a reducir la mortalidad por causas cardiovasculares. Sin embargo, no se conoce ninguna evaluación del efecto del desayuno en el metabolismo energético.

Describimos, por lo tanto, un estudio en el que se investigó el efecto de omitir el desayuno en la ingesta de energía, el gasto de energía en reposo y las concentraciones séricas de glucosa, lípidos e insulina en mujeres sanas delgadas. Participaron 10 mujeres de 19 a 38 años de edad que trabajaban o estudiaban en un centro médico del Reino Unido. Se verificó que tuvieran menstruación regular o tomaran píldoras anticonceptivas y que no estuvieran embarazadas ni lactando ni tuvieran problemas médicos de cuidado. Todas acostumbraban desayunar y cuatro comían cereales de vez en cuando. El estudio se diseñó como un ensayo cruzado aleatorizado con dos intervenciones de 14 días separadas por un intervalo de dos semanas. En una, las participantes se alimentaban con un paquete de cereal integral de $45 \mathrm{~g}$ con $200 \mathrm{~mL}$ de leche con $2 \%$ de grasa (TD) antes de las $8.00 \mathrm{y}$ una galleta dulce recubierta con chocolate entre las $10.30 \mathrm{y}$ las 11.00. En la otra intervención omitían el desayuno (OD) y comían la galleta entre las 10.30 y las 11.00 y el cereal con leche entre las 12.00 y las 13.30. Luego tomaban cuatro comidas adicionales de contenido similar a su dieta corriente a horas determinadas de la tarde. Las participantes siguieron su vida normal durante el ensayo, excepto que registraron su ingesta de alimentos durante dos días de semana y uno de fin de semana antes de iniciar el estudio, así como en los días 3, 11 y 14 de los períodos de TD y OD. Visitaron el laboratorio en el primero y último días de cada intervención (cuatro visitas en total).

Se les pidió a las participantes que ayunaran durante las 10 horas anteriores a las visitas y que no hicieran ejercicio por 48 horas aparte de sus actividades cotidianas normales. A todas, se les midieron el peso, la estatura, y las circunferencias de la cintura y las caderas, y se les extrajo sangre venosa del dorso de la mano. Se les tomaron dos muestras de sangre en ayunas y después de un batido de leche consumido a las 9.00, así como a intervalos de 15 minutos durante 3 horas. Antes y después de cada período se midieron la glucosa en ayunas y después de las comidas, los lípidos, las concentraciones de insulina y el gasto de energía en reposo.

Los resultados indicaron que ni el peso ni las medidas antropométricas o de composición corporal cambiaron de forma significativa después de la intervención. No hubo diferencia significativa entre la glucosa en ayunas antes y después de las visitas ni por efecto de las intervenciones. Las concentraciones de glucosa y de insulina sérica y el ritmo metabólico aumentaron de forma significativa después del alimento de prueba en las cuatro visitas, pero no hubo diferencia significativa en los valores asociados con el ensayo en general. La ingesta energética fue significativamente más baja en el período que incluía desayunos $(P=0,001)$. El área bajo la curva de la respuesta de insulina a la comida del ensayo fue significativamente menor después de tomar el desayuno que después de omitirlo $(P=0,01)$.

Los lípidos plasmáticos tampoco variaron de forma significativa entre visitas al laboratorio, pero se observó un patrón de interacción relacionado con tomar o no el desayuno en la concentración total de colesterol. Esta no cambió de forma significativa tras el período de TD, pero aumentó después del de OD. En este último período aumentó también la concentración del colesterol de lipoproteínas de baja densidad. No se observó ningún resultado significativo en la concentración del colesterol de lipoproteínas de alta densidad. Tampoco hubo diferencia significativa en la concentración de triglicéridos o ácido úrico. Fue interesante que la omisión del desayuno produjera concentraciones más altas del colesterol de lipoproteínas de baja densidad y una sensibilidad posprandial a la insulina más baja. La insulina estimula la hidroxi-metil-glutaril Co-A reductasa, enzima que limita la síntesis del colesterol. La reducción de lipoproteínas de baja densidad después del desayuno quizá se deba a una menor estimulación de la insulina por dicha enzima.

Este estudio muestra que el desayuno afecta a la sensibilidad a la insulina y a las concentraciones de colesterol, y que omitirlo lleva al aumento de peso a largo plazo. Se recomienda tomar el desayuno a pesar de no haberse comprobado sus beneficios. Será necesario llevar a cabo estudios de largo alcance para determinar la magnitud de los efectos observados y su posible interacción con rasgos genéticos. (Farschi HR et al. Deleterious effects of omitting breakfast on insulin sensitivity and fasting lipid profiles in healthy lean women. Am J Clin Nutr. 2005;81(2):388-96.)

\section{La salud de los inmigrantes hispanoamericanos}

Durante los últimos 20 años, a los Estados Unidos de América ha llegado el mayor número de 